\title{
Modulation of Cone Horizontal Cell Activity in the Teleost Fish Retina. III. Effects of Prolonged Darkness and Dopamine on Electrical Coupling Between Horizontal Cells
}

\author{
K. Tornqvist, ${ }^{a}$ X.-L. Yang, ${ }^{b}$ and J. E. Dowling \\ The Biological Laboratories, Harvard University, Cambridge, Massachusetts 02138
}

The effects of prolonged darkness and dopamine on the coupling between horizontal cells in the isolated, superfused white perch retina were studied. Two assays of coupling were employed; area versus amplitude relationships (arearesponse curves) and the diffusion of the fluorescent dye Lucifer yellow from intracellularly injected cells to neighboring cells. In prolonged dark-adapted retinas, area-response curves were difficult to determine because of the small light responses; however, light-evoked responses did not increase in size when light spots were larger than 0.8 $\mathrm{mm}$ in diameter. Following the presentation of dim background illumination that partially sensitized the retina, responses to light spots of various sizes were enhanced and an area-response curve could be constructed. Subsequent presentation of moderate background illumination that more fully sensitized the retina resulted in reduced responses to small spots ( $<1.6 \mathrm{~mm}$ in diameter) and enhanced responses to large spot or full-field stimuli. In retinas exposed to moderate background illumination, Lucifer yellow injected intracellularly into cone horizontal cells diffused into many neighboring horizontal cells. The coupled cells were very similar in morphology, suggesting they were of the same type. In prolonged dark-adapted retinas, on the other hand, the dye was usually restricted to the injected cell and a few adjacent cells. These results indicate that coupling between cone horizontal cells is modulated by prolonged darkness and background illumination.

Following dopamine (50 $\mu \mathrm{M})$ application, in both 6-OHDAtreated and untreated retinas, changes in area-response curves of cone horizontal cells were observed just opposite to those that occurred when prolonged dark-adapted retinas were exposed to background illumination. That is, following $5 \mathrm{~min}$ application of dopamine to the retina, responses to small spots ( $<2 \mathrm{~mm}$ in diameter) increased in size while

\footnotetext{
Reccived Apr. 27, 1987; rcvised Oct. 21, 1987; accepted Oct. 26, 1987.

We are grateful to Ms. S. Levinson for typing the manuscript and to Ms. P. Sheppard for the preparation of the figures. This work was supported by Grants EY 00824 and EY 00811 from the National Institutes of Health. K.T. was supported by the Swedish Medical Research Council (projects B86-14R-7450 and 14X-2321); The Helfrid and Lorenz Nilssons Foundation; The Swedish Institute; The Swedish Society of Medicine; the Fulbright Commission, Stockholm, Sweden; Carin Sandqvist Foundation; and the Faculty of Medicine, University of Lund, Lund, Sweden.

Correspondence should be addressed to John E. Dowling at the above address.

${ }^{a}$ Present address: Department of Ophthalmology, University of Lund, Lund, Sweden.

' Present address: Shanghai Institute of Physiology, Academia Sinica, Shanghai, People's Republic of China.

Copyright (C) 1988 Society for Neuroscience $0270-6474 / 88 / 072279-10 \$ 02.00 / 0$
}

responses to larger spots decreased in amplitude compared with control responses. Following $\mathbf{2 0}$ min of superfusion with dopamine, the recorded responses were very small, and an accurate area-response curve could not be determined. Following dopamine application to light-sensitized retinas, Lucifer yellow was restricted to the injected cells or to the injected cell and a few neighboring cells. The results suggest that the modulation of coupling between cone horizontal cells by prolonged darkness and background illumination may be mediated by dopamine.

Spatial properties of rod horizontal cells were also examined. The responses of these cells increased in amplitude as the light spot increased in size up to $3 \mathrm{~mm}$ in diameter. Neither prolonged darkness nor dopamine appreciably affected the area-response curve of the rod horizontal cells. Significant diffusion of Lucifer yellow between adjacent rod cells did not occur.

In fish and many other animals, horizontal cells are extensively coupled electrically via large gap junctions (Yamada and Ishikawa, 1965; Naka and Rushton, 1967; Witkovsky and Dowling, 1969; Kaneko, 1971). The coupling serves to increase the receptive field size of these cells. For example, the diameters of the dendritic tree of horizontal cells in fish varies from about 30 to $150 \mu \mathrm{m}$ (Stcll and Lightfoot, 1975; Hassin, 1979), but the receptive fields of many fish horizontal cells demonstrated physiologically may be as large as $4 \mathrm{~mm}$ in diameter or larger (Norton et al., 1968; Dowling and Ripps, 1971; Kaneko, 1971; Mangel and Dowling, 1985, 1987).

Horizontal cells lie in sublayers within the inner nuclear layer of the fish retina (Parthe, 1972; Stell and Lightfoot, 1975). The horizontal cells forming a layer are usually morphologically and physiologically distinct from cells of other layers (Mitarai et al., 1974; Hashimoto et al., 1976; Hassin, 1979). In the white perch retina, for instance, 4 types of horizontal cells, located in 4 different sublayers, have been distinguished. These are called $\mathrm{H} 1, \mathrm{H} 2, \mathrm{H} 3$, and $\mathrm{H} 4$ horizontal cells in order of their increasing distance from the photoreceptors (Dowling et al., 1985). The electrical coupling between horizontal cells is specific to cells of the same layer and type. For instance, Kaneko and Stuart (1984) showed that, in the carp retina, Lucifer yellow intracellularly injected into cone horizontal cells giving L-type responses diffused only into surrounding cells with a similar morphology. Such was also the case for the horizontal cells giving C-type responses (Kaneko and Stuart, 1984). Similar observations have also been made in the turtle retina (Piccolino et al., 1984).

In the accompanying papers (Yang et al., 1988a, b) we re- 
Figure 1. Area-response curves of an L-type cone horizontal cell recorded in prolonged darkness and following illumination. The responses to a test flash of constant intensity ( $\log I=-1.56)$ but increasing diameter were recorded and plotted. In the prolonged darkadapted retina, the area-response curve was very flat, and no increase in response amplitude was seen when the spot diameter exceeded $0.8 \mathrm{~mm}$. Following presentation of dim background light $(\log 1=-2.53)$, the responses to all test stimuli were enhanced, and response amplitudes increased with spot diameters up to about $3 \mathrm{~mm}$. After moderate background illumination (Log $I=-1.78$ ) the response-area curve changed its shape so that the responses to small spot $(<2 \mathrm{~mm})$ stimuli were diminished compared with the responses obtained after dim background illumination, whereas responses to larger spot (>2 mm) stimuli were larger than those recorded after dim background illumination.

ported that the light responsiveness of cone horizontal cells in the white perch retina is modulated by prolonged darkness and background illumination and that the dopaminergic interplexiform cells are likely to be involved in this regulation of horizontal cell responsiveness. The data further suggested that the interplexiform cells tonically release dopamine in the dark and that the released dopamine suppresses the light responsiveness of cone horizontal cells.

Several years ago, Negishi and Drujan (1978) showed that the exogenous application of dopamine to the retina decreases the size of horizontal cell receptive fields, suggesting that dopamine alters the electrical coupling between horizontal cells in fish. Subsequently, it was shown in both fish and turtle retinas that dopamine, cyclic AMP, and cyclic AMP-promoting agents all reduce receptive field size of, and dye diffusion between, horizontal cells (Teranishi et al., 1983, 1984; Piccolino et al., 1984), providing evidence for this notion. More recently, Lasater and Dowling (1985) showed directly that dopamine and cyclic AMP decreases the conductance of electrical junctions between horizontal cells by recording simultaneously from pairs of isolated white perch horizontal cells in culture and determining junctional conductance following the application of dopamine or cyclic AMP to the cells. All of these data indicate that dopamine plays a role in the modulation of the spatial properties as well as the light responsiveness of horizontal cells.

In this paper we describe experiments that show how the receptive field properties of horizontal cell responses in the white perch retina, and dye coupling between these cells, are affected by prolonged darkness, background illumination, and dopamine. The results indicate that electrical coupling, like light responsiveness, is modulated by prolonged darkness and that this modulation is likely to be mediated by dopamine.

\section{Materials and Methods}

Details of the preparation, photostimulator, superfusion procedures and intracellular recording techniques were given in the accompanying papers (Yang et al., 1988a, b).

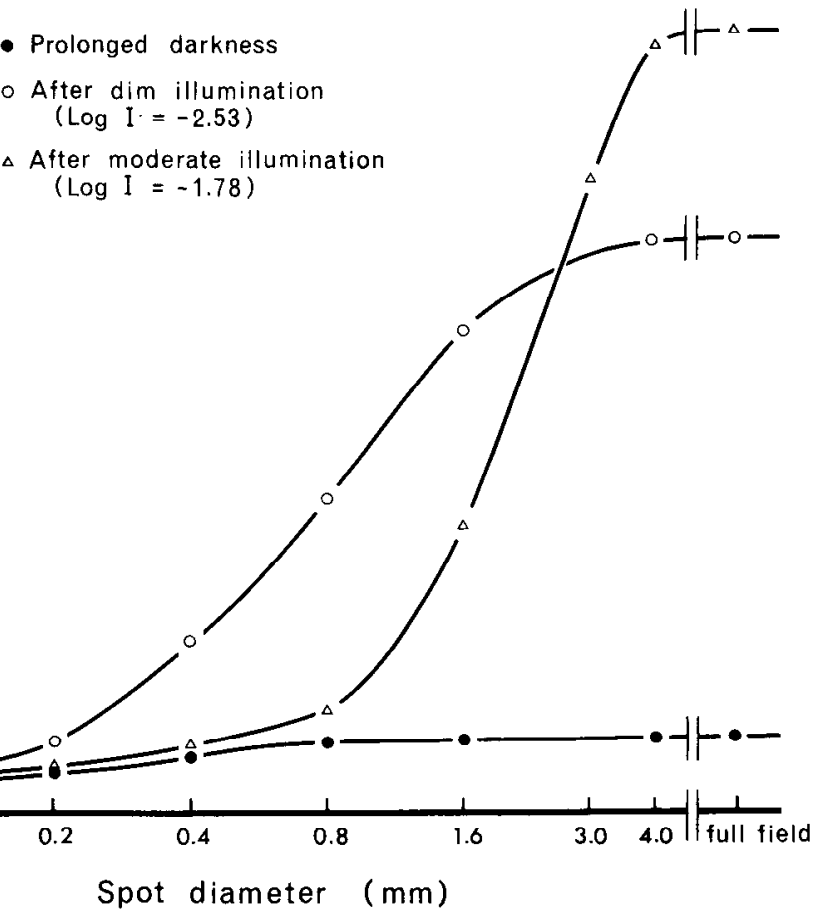

Lucifer yellow injection. The pipettes used for Lucifer yellow injection were filled with $1 \mathrm{~m} \mathrm{LiCl}$ conlaining $4 \%$ Lucifer yellow (Sigma). The resistance of the electrodes was about $50 \mathrm{M} \Omega$. When a cell had been impaled and identified, square wave pulses (duration, $400 \mathrm{msec}$, duty factor, $1 \mathrm{sec})$ of hyperpolarizing current $(10-20 \mathrm{nA})$ were used to inject dye into the cells. Injection times of about 10-15 min were used. Intracellular responses from the injected horizontal cells were monitored during the injection period, and responses to light usually remained after Lucifer yellow injection.

After injection, retinas were left in the perfusion chamber for $30 \mathrm{~min}$ to allow dye diffusion and were then fixed in $4 \%$ formalin solution (40 gm formaldehyde dissolved in 1 liter of $0.1 \mathrm{M}$ phosphate buffer, $\mathrm{pH} 7.4$ ) for $24 \mathrm{hr}$. They were rinsed in $0.1 \mathrm{M}$ phosphate buffer, dehydrated, and cleared in increasing concentrations of ethanol and xylene. The dehydration procedure was performed in a petri dish with the hemiretinas stretched on a microscope slide. The retinas were flat-mounted in Eukitt with the ganglion cell layer up and examined in a Zeiss fluorescence microscope with EPI-illumination.

To evaluate quantitatively dye spread between horizontal cells, we routinely counted all of the cells adjacent to the dye-injected cell that showed significant fluorescence. Since the fluorescence intensity is graded with distance from the injected cell, it is often difficult to decide whether a cell shows significant fluorescence. Our criterion was to count a cell as showing significant fluorescence if it could be seen both before and after a $1 \log$ unit filter was placed in the light path of the microscope.

\section{Results}

Modulation of spatial properties of cone horizontal cell responses by darkness and illumination

Figure 1 shows area-response curves, recorded in a single L-type cone horizontal cell, in prolonged darkness $(2 \mathrm{hr})$ and following presentation of background lights of increasing intensity. In this experiment, responses of the cell were elicited with spot stimuli of various diameter but constant intensity ( $\log I=-1.56$ ). Responses of cone horizontal cells recorded in prolonged darkness were very small, and response amplitudes did not exceed $5 \mathrm{mV}$ regardless of stimulus size. Thus, the area-response curve determined in prolonged darkness was very flat. However, the responses did show perceptible increases in amplitude up to a spot sizc of $0.8 \mathrm{~mm}$ but then did not show any further changes in amplitude when the light spots increased from 0.8 to $4 \mathrm{~mm}$ 


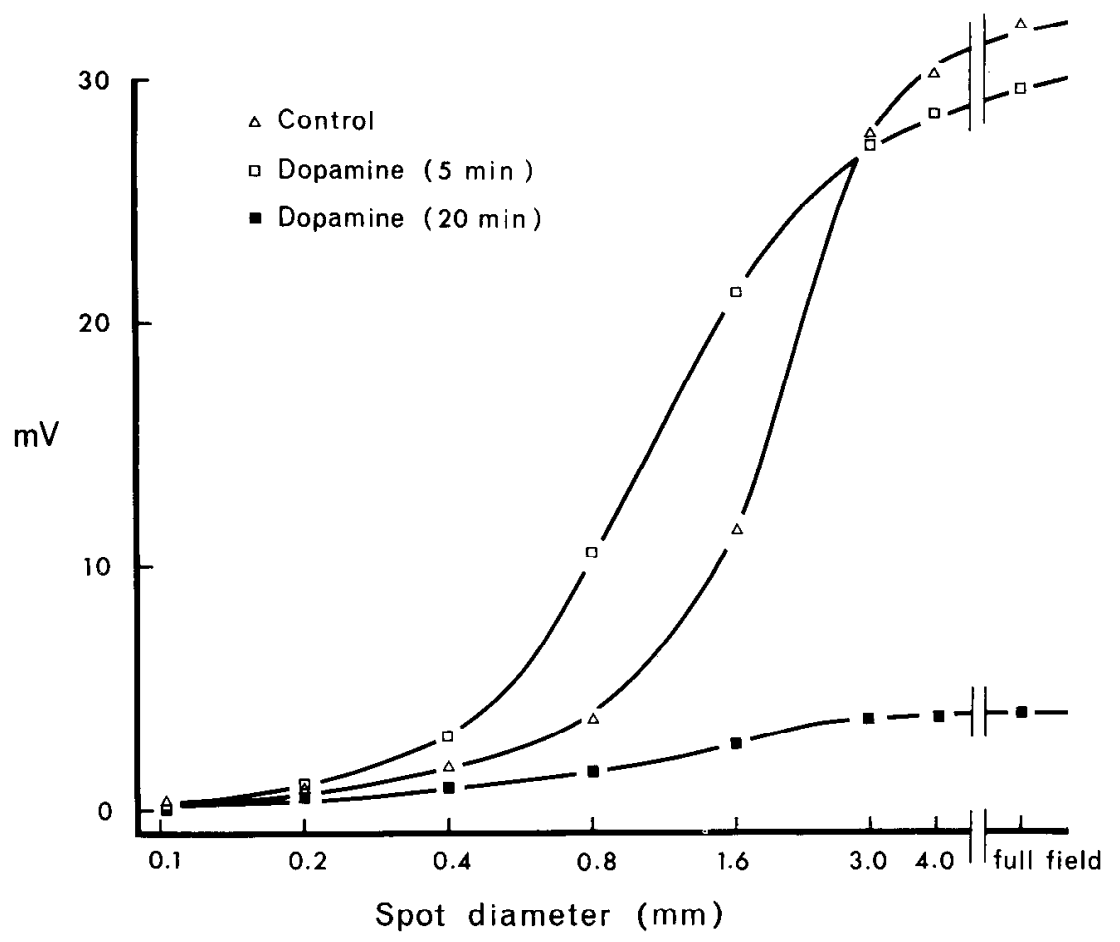

Figure 2. Area-response curves of an L-type cone horizontal cell before and after dopamine application $(50 \mu \mathrm{M})$ to a light-sensitized (control) retina. After 5 min of dopamine application (open squares), responses to small spot $(<2$ $\mathrm{mm}$ ) stimuli increased in size, whereas responses to large spot and full-field stimuli were reduced in size compared with those recorded before dopamine application. After a longer period (20 min) of dopamine application (filled squares), the area-response curve was very flat and closely resembled the curve obtained in prolonged dark-adapted retinas (Fig. 1). in diameter. These results suggest that the cell had a relatively small receptive field under prolonged dark-adapted conditions.

Following a 10 min presentation of dim background light (Log $I=-2.53$ ) to the retina, response amplitudes to flashes of all sizes were enhanced and a reliable area-response curve could be detcrmined. Responses increased significantly in amplitude with increasing size of the light spot and appeared to saturate at a spot size of about $3 \mathrm{~mm}$. Following a subsequent $3 \mathrm{~min}$ presentation of moderate background light $(\log I=-1.78)$, the area-response curve was significantly changed in shape. Compared with responses recorded following the dim background illumination, responses to small spot ( $<2 \mathrm{~mm}$ diameter) stimuli decreased in size, while responses to large spot $(>2 \mathrm{~mm}$ diameter) or full-field stimuli further increased in size. Thus, following moderate background illumination, the response significantly increased in size until the light spot exceeded $4 \mathrm{~mm}$ in diameter. In all 5 cells studied (both L- and C-type), we observed similar changes in spatial properties of the responses. The results indicate that the cells greatly expanded their receptive fields after presentation of background lights, demonstrating that spatial properties of cone horizontal cells are modulated by background illumination.

\section{Effects of dopamine on spatial properties of cone horizontal cell responses}

We next examined the effects of dopamine application on the area-response curves of cone horizontal cells. These experiments were performed on cells from retinas previously exposed to moderate background illumination $(\log I=-1.78)$. The light responsiveness of cone horizontal cells in such retinas was enhanced to a maximum level, and it remained high even when the retina was maintained in complete darkness for long periods of time (see previous papers, Yang et al., 1988a); this will be referred to as the control condition in this paper. Figure 2 shows area-response curves recorded from a single L-type cone hori- zontal cell under the control condition at different times following dopamine $(50 \mu \mathrm{M})$ application to the retina. Following $5 \mathrm{~min}$ exposure of the retina to dopamine, responses to spot stimuli $<2 \mathrm{~mm}$ in diameter increased in size, while responses to larger spot or full-field stimuli slightly decreased in size compared with responses recorded before drug application. When dopamine was applied for longer periods of time, responses to both small and large spot stimuli were considerably reduced. Thus, the arearesponse curve recorded $20 \mathrm{~min}$ after the onset of dopamine application was very flat. However, maximal response amplitudes were elicited with spots of smaller diameter than was the case in the control situation or after 5 min of dopamine exposure. These changes in the area-response curve of cone horizontal cells following dopamine application were opposite those that occurred when prolonged dark-adapted retinas were exposed to background lights of increasing intensity.

Figure 3 shows the changes in response amplitudes of an L-type cone horizontal cell, recorded in a light-sensitized retina superfused with Ringer's containing dopamine, to a small light spot stimulus $(0.4 \mathrm{~mm}$ diameter) as a function of time. In the first $7 \mathrm{~min}$ of dopamine application, the response of the cell to the small spot significantly increased in amplitude, from 15 to $25.5 \mathrm{mV}$, and the initial on-transient of the response became more pronounced, as shown in the lower part of Figure 3 . Thereafter, the responses gradually decreased in size, and following 17 min of dopamine application the response amplitude was only about $3 \mathrm{mV}$. The decrease in response amplitude was accompanied by noticeable changes in response waveforms; for example, the on-transient became less conspicuous and cventually disappeared. Dopamine superfusion was terminated at this point and the retina washed with normal Ringer's. The trace and data point on the far right are from another cell impaled 78 min after dopamine application ceased, showing that partial recovery of response amplitude had occurred.

Similar changes were observed when dopamine was applied 
Figure 3. Changes in response amplitudes and response waveforms of an L-type cone horizontal cell during the application of $50 \mu \mathrm{M}$ dopamine to a light-sensitized retina. Initially, the response to the small spot flash increased in amplitude and the on-transient of the response became more pronounced. Approximately $8 \mathrm{~min}$ after the onset of drug application, responses to the small test flashes began to decrease, and by 15 min they were only a few millivolts in amplitude. Dopamine application was stopped at $17 \mathrm{~min}$, and the retina was then washed with normal Ringer's. After $95 \mathrm{~min}$, a response recorded from another horizontal cell (filled square) indicated that partial recovery had occurred.

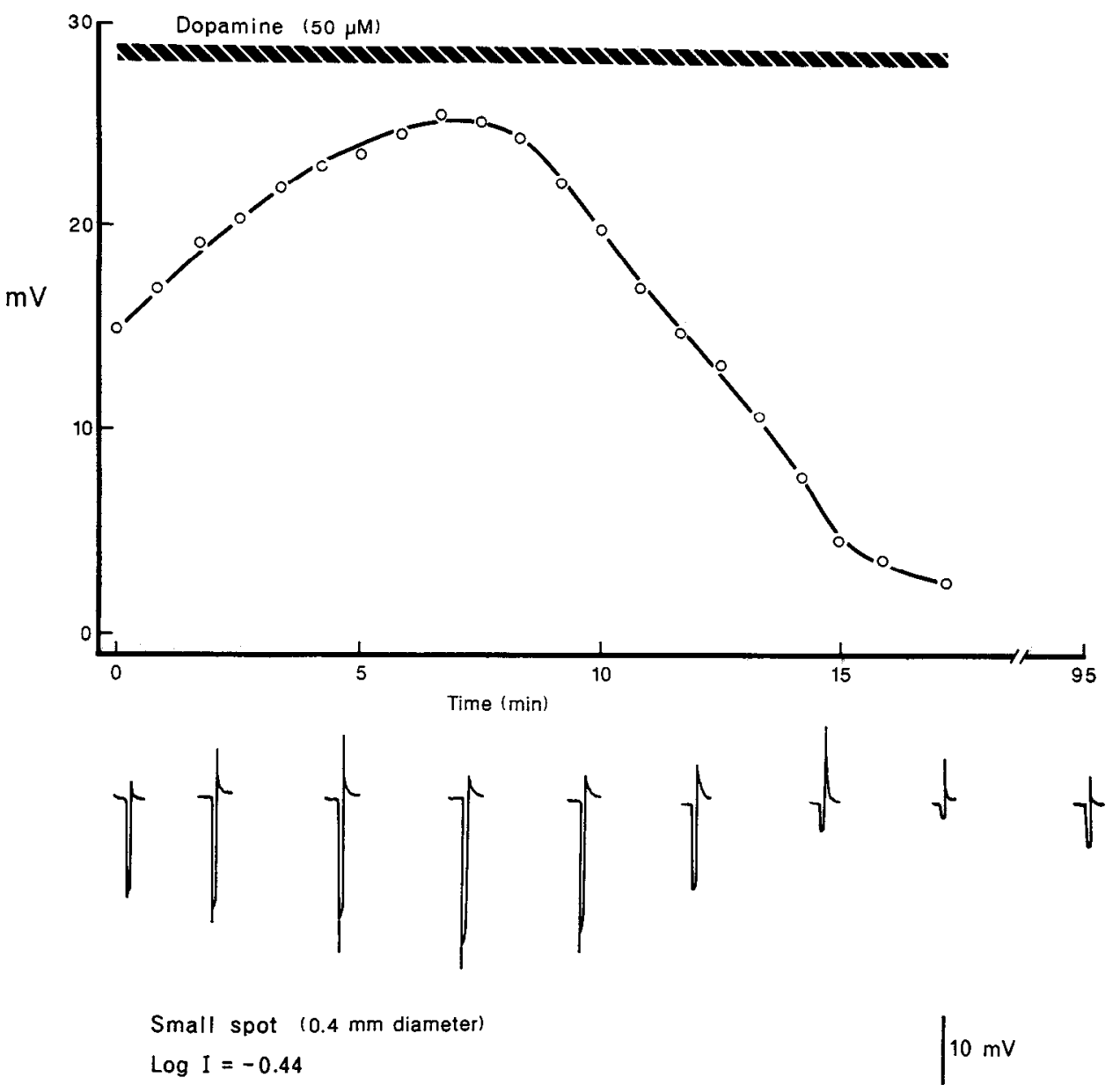

to 6-OHDA-treated retinas $(n=4)$. Figure 4 depicts a result obtained from an L-type cone horizontal cell in a 6-OHDAtreated retina recorded in prolonged darkness. The response to the small spot stimulus $(0.4 \mathrm{~mm}$ diameter, $\log I=-0.44)$ increased from 26 to $33 \mathrm{mV}$ in the first $5 \mathrm{~min}$, but thereafter it started to decrease, and $17 \mathrm{~min}$ after the onset of dopamine application was only $3 \mathrm{mV}$. Again, dopamine application was terminated after $17 \mathrm{~min}$ and the retina washed with normal Ringer's. A cell penetrated about an hour later showed evidence of partial recovery of response amplitude (data point and record at $80 \mathrm{~min}$ ).

The changes in response amplitudes to a small spot of light that are illustrated in Figures 3 and 4 reflect at least 2 phenomena occurring in response to dopamine: uncoupling of the horizontal cells and a loss of light responsiveness. That the responses grow substantially in the first $5 \mathrm{~min}$ or so of dopamine application but then decrease in amplitude over the next 10 min suggests the possibility that the uncoupling of the horizontal cells occurs more rapidly than the loss of light responsiveness (see Figs. 4 and 7 in the preceding paper).

\section{Modulation of dye coupling between cone horizontal cells by darkness and illumination}

Although the experiments described so far suggest that the spatial properties of cone horizontal cells in the white perch retina are modified by prolonged darkness and dopamine, responses of cells recorded in retinas maintained in prolonged darkness, or in light-sensitized retinas exposed to dopamine, were too small to make confident or quantitative statements concerning the shrinkage of their receptive fields under these conditions. We therefore examined the extent of dye spread between horizontal cells under these different conditions.

When Lucifer yellow was injected into a cone horizontal cell in a light-sensitized retina, dye usually diffused into many neighboring cells. Figure 5, top, illustrates an experiment in a prolonged dark-adapted retina previously exposed to moderate background illumination $(\log I=-1.78)$. The injected cell, located in the center of the micrograph, could be identified by its intense fluorescence. 'This cell hyperpolarized in response to all the wavelengths and had a spectral sensitivity maximum at around $600 \mathrm{~nm}$. The dye diffused from this cell into many neighboring cells, revealing a dense network of interconnected cells. All of the coupled cells displayed a morphology similar to that of the injected cell; i.e., they all appeared to be of the same type. The number of cells showing significant Lucifer yellow fluorescence in a light-sensitized retina was usually around 30 (mean of 31 in 18 injected cells). The cells shown in Figure 5, lop, are $\mathrm{H} 2$ cells; similar results were observed with $\mathrm{H} 3$ cells, which are C-type cells. Only 2 of the small $\mathrm{H} 1$ cells were injected with Lucifer yellow, but both showed extensive coupling to adjacent $\mathrm{H} 1$ cells.

In prolonged ( $>2 \mathrm{hr}$ ) dark-adapted retinas spread of dye between horizontal cells was significantly restricted. Figure 5, bottom, shows an example of a Lucifer yellow injected L-type cone horizontal cell in a retina maintained in prolonged darkness. The cell had the same morphology as the cell illustrated in Figure 


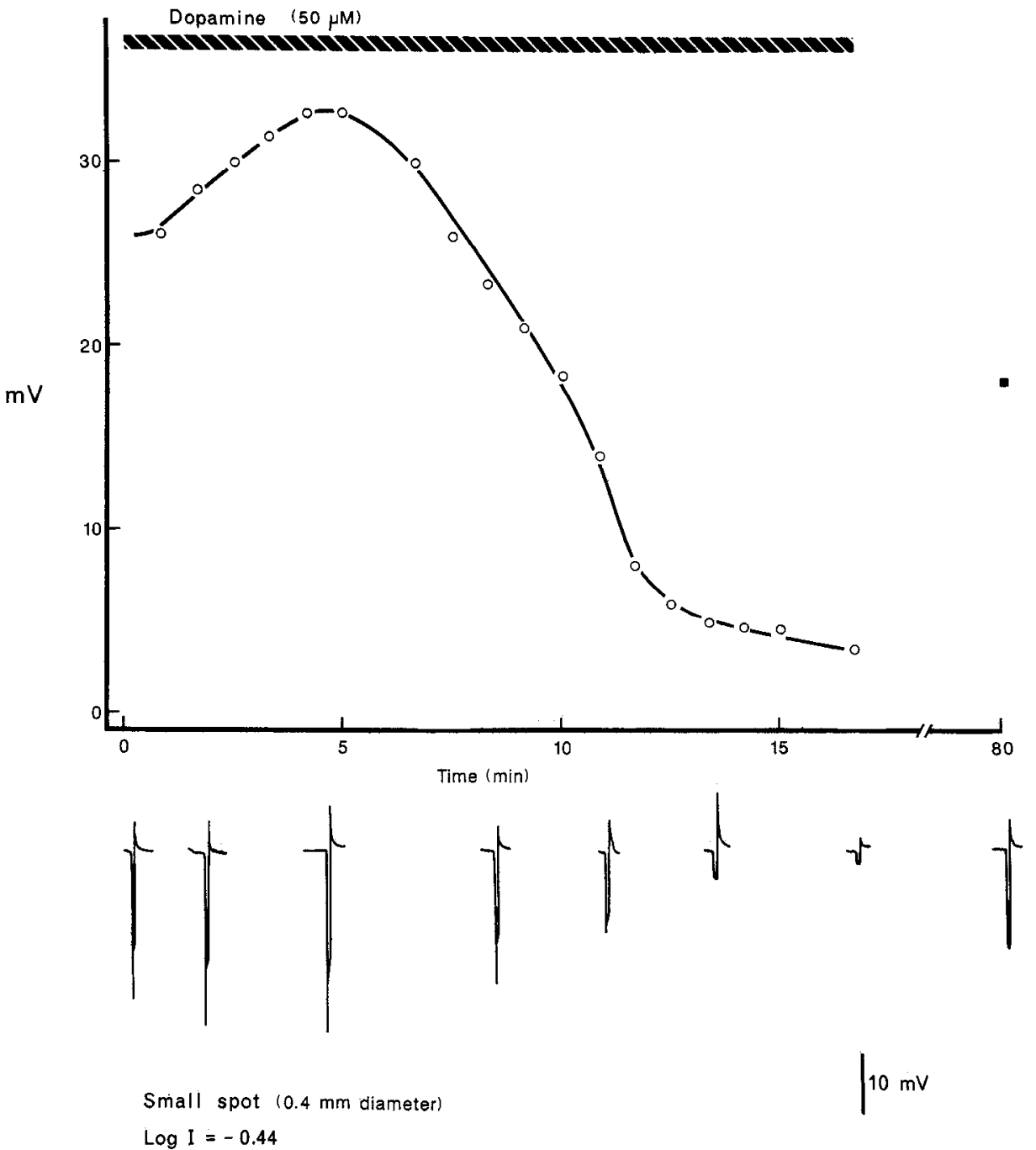

Figure 4. Changes in response amplitudes and response waveform of an L-type cone horizontal cell during the application of $50 \mu \mathrm{M}$ dopamine to a 6-OHDA-treated retina maintained in prolonged darkness. Initially, the responses to the spot stimulus $(0.4 \mathrm{~mm})$ increased in amplitude, but after about 5 min the amplitudes decreased. By 15 min the responses evoked were only a few millivolts. Dopamine application was stopped at $17 \mathrm{~min}$, and the retina was washed thereafter with normal Ringer's. At $80 \mathrm{~min}$, a response recorded from another cell (filled squares) indicated that the retina had partially recovered.
5 , top. However, even though the same current and injection time as for the cell shown (Figure 5, top) was used, only a few adjacent cells showed any fluorescence. Further, the intensity of the fluorescence in the cells, other than the injected cell, was very weak. In a total of 17 injected cells in prolonged darkadapted retinas exposed only to test flashes presented at intervals of $30 \mathrm{sec}$, we observed significant dye spread to an average of 4.4 cells. In a few instances, no dye spread at all was noted from a ccll injected in a prolonged dark-adapted retina.

\section{Modulation of coupling between cone horizontal cells by dopamine}

When a retina exposed to moderate background illumination was superfused with Ringer's containing $50 \mu \mathrm{M}$ dopamine, dye spread between cone horizontal cells was also significantly restricted. Figure 6, top, shows an example. In this micrograph, 2 cells of different morphology can be distinguished. The responses of the cell more in focus and showing more intense fluorescence were biphasic, i.e., the cell hyperpolarized to shortwavelength flashes, but depolarized to long-wavelength ( $>680$ $\mathrm{nm}$ ) flashes, and its morphology was similar to $\mathrm{H} 3$ cells in the white perch. The cell showing much less fluorescence was located more distally in the retina and had the morphology of cells showing L-type responses, i.e., an $\mathrm{H} 2$ cell. Although it was thought that dye was injected only into the C-type cell, it is likely that some dye passed into the L-type cell during the injection. However, neither cell appeared to allow dye spread to adjacent cells. Commonly, following dopamine application, dye was observed to spread to a few surrounding cells. Thirty-three cells were injected after dopamine $(50 \mu \mathrm{M})$ application to the retina, and on average we observed 4.1 cells coupled to the injected cell. These results are very similar to those obtained in prolonged dark-adapted retinas.

\section{Spatial properties of rod horizontal cells}

We also determined area-response curves in 6 rod horizontal cells, a typical result being shown in Figure 7 . The cell showed larger responses with increasing diameter spots up to $3 \mathrm{~mm}$, suggesting that its receptive field was on the order of $3 \mathrm{~mm}$ in diameter. Examination of the relationship between the sensitivity and the spot size (Fig. 7, inset) led to the same conclusion. In this experiment the sensitivity was defined as the reciprocal of the light intensity eliciting a $5 \mathrm{mV}$ criterion response and was plotted as a function of spot size. When the diameter of the spot was $<3 \mathrm{~mm}$, the relation between sensitivity and area was almost linear, but it saturated abruptly once the spot diameter exceeded $3 \mathrm{~mm}$.

Rod horizontal cells injected with Lucifer yellow showed a 

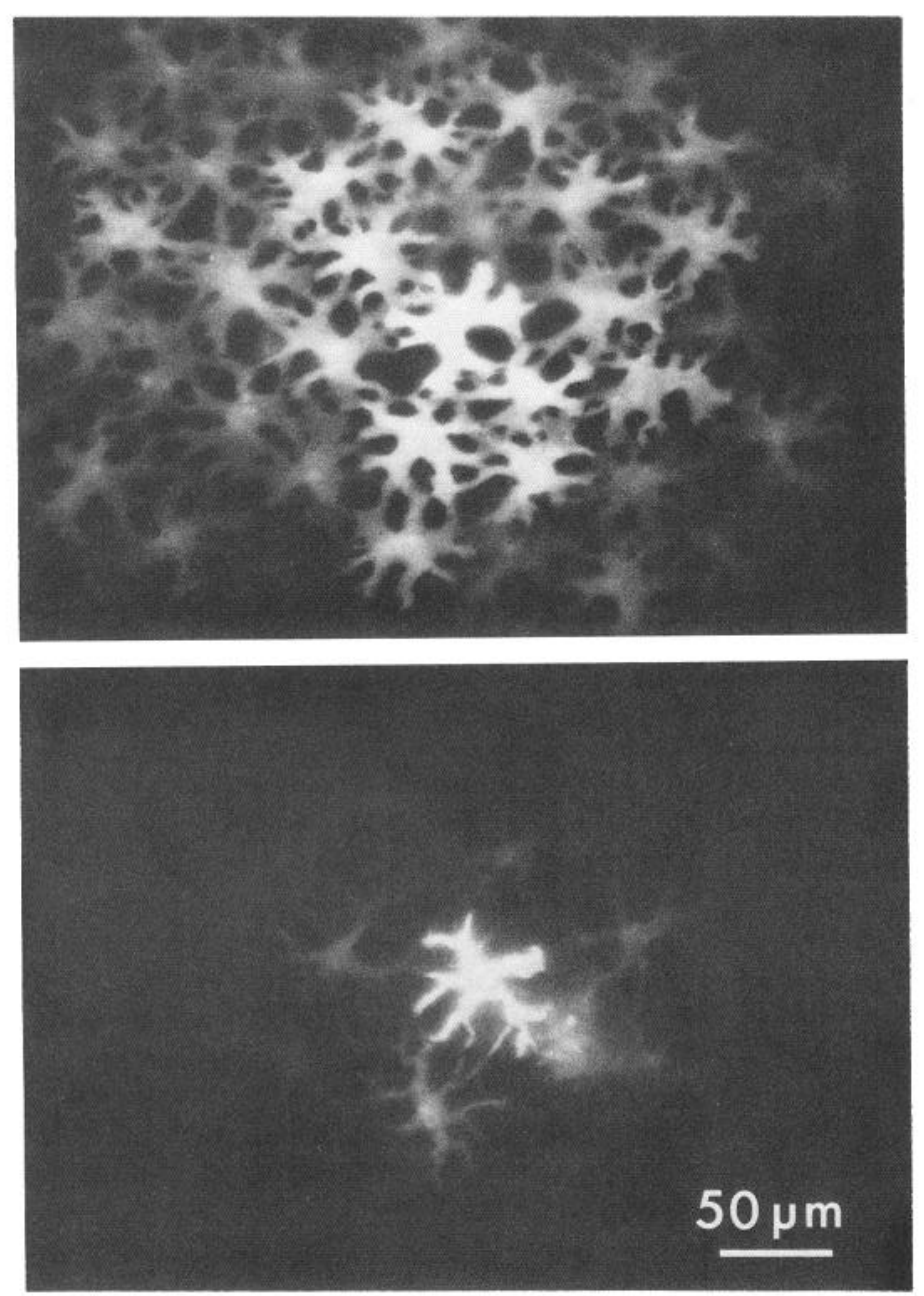

Figure 5. Top, Lucifer yellow-injected cells in a light-sensitized retina. The dye was presumably injected into the $\mathrm{H} 2$ cell in the center of the micrograph that shows the brightest fluorescence. $\mathrm{H} 2$ cells are characterized by a larger cell body and short stout processes. The dye diffused into a large number of surrounding cells; i.e., a considerable amount of dye coupling is seen. This cell was injected for 14 min with $20 \mathrm{nA}$ hyperpolarizing current pulses. Bottom, Lucifer yellow-injected cells in a prolonged dark-adapted retina. The injected cell (center) is of the $\mathrm{H} 2$ type with short, stout processes, slightly branched at the endings. Dye diffused into only a few surrounding cells, and these cells show only weak fluorescence. This cell was injected for $15 \mathrm{~min}$ with $20 \mathrm{nA}$ hyperpolarizing current pulses. Fluorescence micrograph calibration bar, $50 \mu \mathrm{m}$.

morphology different from that of cone horizontal cells (Fig. 6, bottom). The cell body was about the same size as that of C-type (H3) cells and clearly smaller than the cell body of the $\mathrm{H} 2$ cells. The processes of the cells were considerably thinner and longer than the processes of any type of cone horizontal cells and usually split into $2-4$ secondary processes and sometimes finer tertiary processes. These cells were similar to the $\mathrm{H} 4$ cells observed in the white perch retina. A surprise was that no significant spread of dye to surrounding cells was ever seen with rod horizontal cells $(n=5)$.

\section{Discussion}

In this paper we have shown that the spatial properties of cone horizontal cells in the white perch are altered by prolonged darkness and background illumination. The light-evoked re-
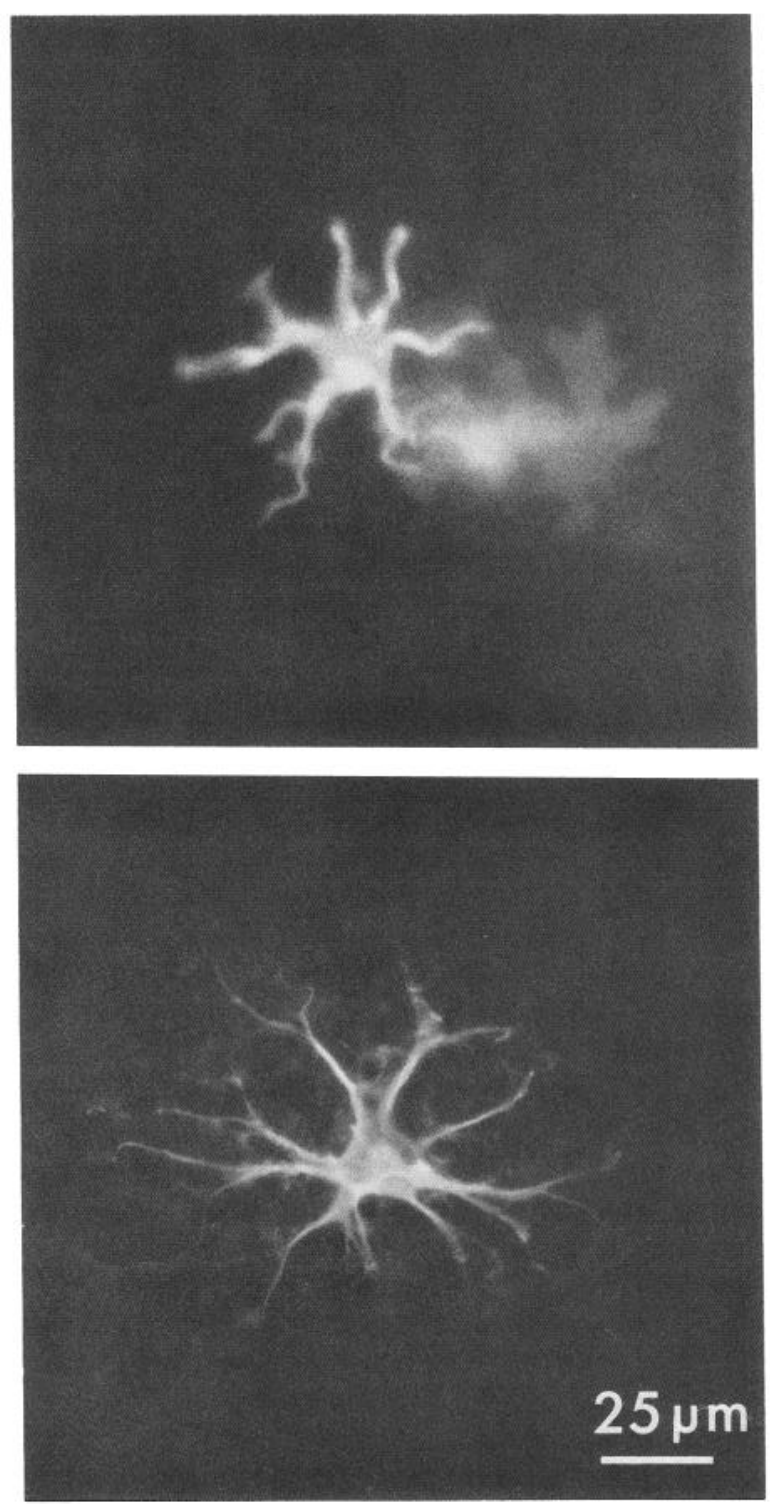

Figure 6. Top, Lucifer yellow-injected cells in a light-sensitized retina superfused with $50 \mu \mathrm{M}$ dopamine. The cell with the brighter fluorescence is an $\mathrm{H} 3$ cell with thin nonbranched processes. The adjacent, less fluorescent cell is of the H2-type with short, stout, slightly branched processes. The $\mathrm{H} 3$ cell was injected with $20 \mathrm{nA}$ hyperpolarizing current for $10 \mathrm{~min}$. The dye in the $\mathrm{H} 2$ cell probably diffused from the electrode before or after injection (see text). Bottom, Lucifer yellow-injected rod horizontal cell; an $\mathrm{H} 4$ cell. The cell body is rounded, and its processes are very thin, long, and branched. This cell was injected in a darkadapted retina; injection time was $10 \mathrm{~min}$ and current $15 \mathrm{nA}$. No significant amount of dye diffusion was observed. Calibration bar, $25 \mu \mathrm{m}$.

sponses of cone horizontal cells recorded in prolonged darkadapted retinas are small, and area-response curves are difficult to determine. Nevertheless, response amplitudes reached maximum values with $0.8 \mathrm{~mm}$ diameter spots, suggesting that the receptive fields of cells in prolonged dark-adapted retinas were $<1 \mathrm{~mm}$ in diameter.

Following dim background illumination, responses of the cone horizontal cells grew in amplitude, and larger spots were now required to give maximal horizontal cell responses. Increasing background illumination sensitized the cells further and also significantly changed the shape of the area-response curve. The curve obtained following moderate background illumination was 


\section{Rod Horizontal Cell}

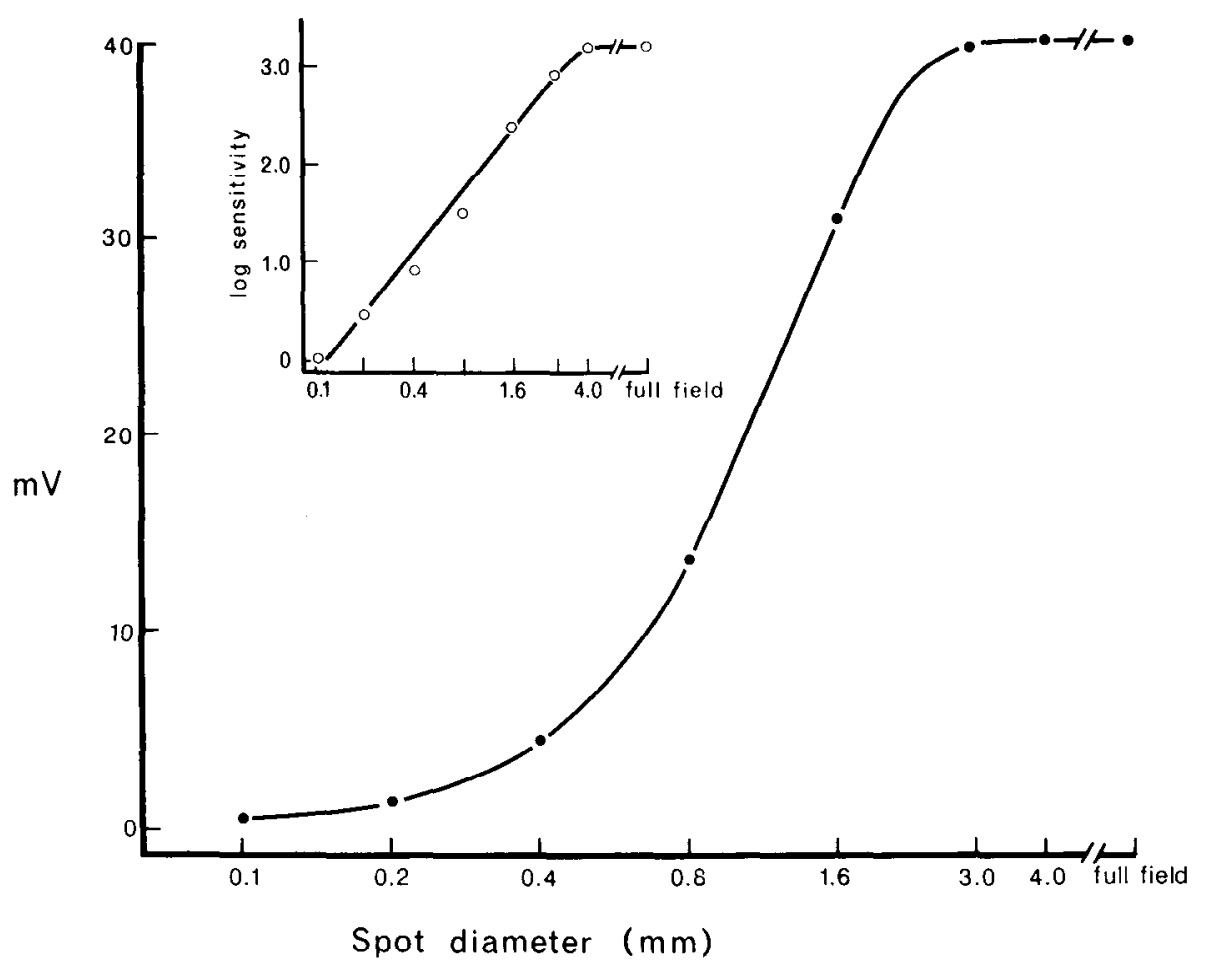

Figure 7. Area-response curve of a rod horizontal cell. The inset shows the relationship between sensitivity of the cell and spot size. Both sets of data indicate a receptive field size of about $3 \mathrm{~mm}$ for the cell. Sensitivity was defined as the reciprocal of the light intensity eliciting a $5 \mathrm{mV}$ response.

steeper than that recorded following dim background illumination; furthermore, responses to small light spot stimuli $(<1.6$ $\mathrm{mm}$ in diameter) were considerably smaller in amplitude, whereas responses to larger spot stimuli were significantly larger. The differences in responses obtained following dim and moderate background lights in white perch were reminiscent of those observed between cells recorded in prolonged $(100 \mathrm{~min})$ and shortterm (30 min) dark-adapted carp retinas: In prolonged darkness in carp, responses to small spot stimuli $(<1.6 \mathrm{~mm}$ in diameter) were larger, but responses to larger spot stimuli were smaller (Mangel and Dowling, 1985, 1987) than in short-term darkadapted retinas. These results suggest that the electrical coupling between cone horizontal cells is modulated by prolonged darkness and background illumination. That is, if the conductance of gap junctions between cone horizontal cells is less in retinas dimly illuminated compared with retinas exposed to moderate illumination, larger response amplitudes to small spot stimuli are expected because less current can be shunted from cells in the illuminated area to cells in the dark surrounding region and a larger voltage develops across the membrane of cells in the illuminated area.

In prolonged dark-adapted retinas, all light-evoked responses are very small (Yang et al., 1988a), making it difficult to obtain evidence of coupling changes between cells based on electrophysiological recordings. The injection of Lucifer yellow into cells provides an effective method of evaluating electrical coupling under these circumstances. This dye has been demonstrated to pass across many gap junctions and to diffuse into neighboring cells (Stewart, 1978; Teranishi, 1983; Kaneko and Stuart, 1984; Piccolino et al., 1984; Teranishi et al., 1984). In the lightsensitized horizontal cells, we observed that Lucifer yellow injected into a single cell diffused into many adjacent cells, forming a dense network of fluorescent cells. All of the cells showing fluorescence were similar in morphology, indicating that the coupling between horizontal cells in white perch is limited to cells of the same type.

In cells injected with Lucifer yellow in retinas maintained in prolonged darkness, only a slight spread of the dye to 4-5 neighboring cells was typically observed. Although dye diffusion between cells will be influenced by the amount of current injected and the time allowed for diffusion, control experiments demonstrated that dye diffusion was essentially independent of these 2 parameters in horizontal cells, provided injection current and time exceeded $10 \mathrm{nA}$ and $10 \mathrm{~min}$, respectively. Indeed, very consistent results were obtained in experiments carried out under the same conditions of retinal illumination and/or dopamine application. In 18 cells injected in prolonged dark-adapted retinas, we counted an average of 4.4 cells coupled to the injected cells, whereas in 17 cells injected in light-sensitized retinas, an average of 31 cells was observed surrounding the injected cell. It is clear that the extent of electrical coupling between horizontal cells far exceeds that of detectable dye coupling between horizontal cells. That is, the area-response curves for light-sensitized horizontal cells suggest that the receptive fields of these cells is approximately $3-4 \mathrm{~mm}$ in diameter (Fig. 1). On the other hand, the field of cells showing any fluorescence following injection of Lucifer yellow into a horizontal cell is at most about $1 \mathrm{~mm}$ in diameter (Fig. 5, top). Nevertheless, the differences in dye diffusion, and hence coupling, between cells in prolonged dark-adapted and light-sensitized retinas are highly significant.

Earlier work showed that dopamine induces a shrinkage of the cone horizontal cell receptive fields and that it restricts dye diffusion between these cells (Teranishi et al., 1983, 1984). Furthermore, it was demonstrated that dopamine reduced the conductance of gap junctions between coupled pairs of isolated horizontal cells in culture (Lasater and Dowling, 1985). Our 
findings are in agreement with these results. After application of Ringer's containing dopamine to light-sensitized retinas, $\mathrm{Lu}$ cifer yellow was restricted to the injected cell or diffused at most to 5-6 surrounding cells. We found that in 19 injected cells significant fluorescence was observed in an average of 4.1 cells surrounding the injected cell. This result is very similar to that found in cells injected in prolonged dark-adapted retinas, and suggests that the decrease in coupling between horizontal cells in prolonged dark-adapted retinas is mediated by dopamine.

Further evidence that dopamine mediates changes in receptive field size depending on the adaptive state of the retina comes from measurements of area-response curves during dopamine application to the retina. Following a 5 min exposure of a retina to dopamine, responses to small spot stimuli ( $<2 \mathrm{~mm}$ diameter) increased in size, while responses to large spot or full-field stimuli became smaller compared with the area-response curve in a control, light-sensitized retina. These changes were essentially the opposite of those observed in area-response curves following dim and moderate background illumination of prolonged darkadapted retinas. Furthermore, following a 20 min application of dopamine to the retina, only a very flat area-response curve could be obtained. Like the results presented in the preceding papers, these data show that the light responsiveness of cone horizontal cells is suppressed in prolonged darkness and that dopamine mimics the effect of prolonged darkness. They also provide further evidence that dopamine is tonically released by interplexiform cells in prolonged darkness, and we conclude that the released dopamine decreases the light responsiveness of individual horizontal cells and reduces electrical coupling between adjacent horizontal cells.

As yct, little is known about the mechanisms regulating dopamine release from interplexiform cells in fish. No likely neurotransmitter substance has been found that releases dopamine from the fish retina. On the other hand, GABA antagonists readily release dopamine from fish and other retinas, suggesting that interplexiform cells are under strong inhibitory control by GABAergic amacrines. It is possible that the release of dopamine from interplexiform cells is mainly regulated in this way, by inhibitory neurotransmitter control, but this remains to be shown. An interesting and intriguing recent finding is that centrifugal fibers that contain the peptides leutenizing hormone releasing hormone and FRMFamide make synapses on the interplexiform cell perikarya and proximal processes in the white perch retina (Stell et al., 1984; Zucker and Dowling, 1987). What effect these peptides have on the interplexiform cells and the release of dopamine in the retina is unknown. However, these observations do suggest that interplexiform cell activity and dopamine release in the retina are influenced by central mechanisms.

The effects of prolonged darkness on cone horizontal cells are not obvious for at least $30-40 \mathrm{~min}$ after illumination is withheld from a retina. Why there is such a long delay between the onset of darkness and the postulated release of dopamine is not at all clear. One known retinal mechanism that requires this length of time is the regeneration of rod visual pigment, which in many species takes 20-60 min or longer. The evidence so far suggests, however, that the modulation of horizontal cell responses in the teleost is independent of rod activity. That is, background illumination that strongly activates rod horizontal cell activity but is below cone horizontal cell threshold has no effect on the responsiveness of cone horizontal cells in prolonged dark-adapted retina. To restore responsiveness to horizontal cells in pro- longed dark-adapted retinas requires light of sufficient intensity to activate the cone system. These observations indicate the modulation of cone horizontal cells by prolonged darkness and background illumination is mediated entirely by cone system.

\section{Cone and rod horizontal cells in the white perch retina}

In the white perch retina 4 layers of horizontal cells can be distinguished (Dowling et al., 1985). Four morphologically distinct horizontal cells have been described in the white perch and correlated with the 4 horizontal cell layers. These cells have been labeled $\mathrm{H} 1-\mathrm{H} 4$ cells in order of their location relative to the receptors. Electrophysiological results (Yang et al., 1988a) showed that when an electrode was advanced into the retina from the receptor side, L-type cone responses were first recorded. C-type cells were next impaled, and rod horizontal cells were impaled only after the electrode had penetrated through both the L- and C-type cone horizontal cells. In this study, most of the cells $(95 \%, n=39)$ showing L-type responses had a morphology similar to that of the cells shown in Figure 5. Based on location, morphology, and size of these cells, they were judged to be $\mathrm{H} 2$ cells. Cells similar in morphology to the smaller $\mathrm{H} 1$ cells were rarely encountered, and only 2 injected cells were detected. These 2 cells had light-induced responses that could not be distinguished from that of the $\mathrm{H} 2$ cells. The C-type cell illustrated in Figure 7 closely resembles in morphology the white perch $\mathrm{H} 3$ cells, which have a slightly smaller, sometimes elongated perikaryon and longer and thinner primary processes than the $\mathrm{H} 2$ cells.

The H1-H3 cells in the white perch closely resemble the conedriven horizontal cells of the pikeperch, in which it was shown that the II 1 and $\mathrm{H} 2$ cells were L-type and the $\mathrm{H} 3$ a C-type cell (Hassin, 1979). Rod horizontal cells were not detected in pikeperch, but Witkovsky et al. (1979) pointed out that a rod horizontal cell must be present. It was suggested earlier that the $\mathrm{H} 4$ cell in the white perch may be a rod-related horizontal cell, and our results show that the rod horizontal cells are very similar in morphology to the $\mathrm{H} 4$ cells (Fig. 6, bottom). Of all the types of horizontal cells in white perch retina, it has the finest primary processes, and these usually split into 2 or more secondary and finer tertiary processes.

Though the dendritic tree of the rod horizontal cells usually extends only $100-150 \mu \mathrm{m}$ in diameter, their receptive fields are about $3 \mathrm{~mm}$ in diameter. This indicates that rod horizontal cells are electrically coupled with one another. It was thus a surprise that Lucifer yellow was usually restricted to the injected rod horizontal cell and that no significant spread of the dye between cells could be observed. A similar obscrvation has been reported in the carp, where only minimal dye diffusion occurs between rod horizontal cells (Teranishi et al., 1984). Why this is so is not clear. It may be that the gap junctions between the rod horizontal cells are small in relation to cell volume, so that dye diffusion is difficult to visualize, or it may be that the gap junctions of rod horizontal cells are somewhat different from those of cone horizontal cells and are relatively impermeable to Lucifer yellow molecules.

\section{General conclusions}

In this series of papers, we have provided evidence that the responses of cone-driven horizontal cells in the white perch retina are dramatically affected by prolonged darkness and that background illumination is needed to maintain both vigorous light responsiveness of, and extensive electrical coupling be- 
tween, these horizontal cells. Similar results have been observed in the carp retina, although the effects of prolonged darkness are not nearly as dramatic in the isolated carp retina as in the isolated white perch retina. The data thus suggest that the suppression of cone horizontal cells by prolonged darkness may be a general phenomenon in fish, and a similar phenomenon may occur in other animals as well. That is, it has long been known that the antagonistic surround responses of ganglion cells in a variety of animals are suppressed or absent following prolonged darkness, and it is believed that the surround antagonism observed in the ganglion cell responses derives in large measure from the horizontal cells.

In fish, the suppression of horizontal cells by prolonged darkness is limited to the cone horizontal cells; rod horizontal cells have not been shown to alter light responsiveness or coupling depending on the adaptive state of the retina. It may be that cone pathways are selectively depressed in prolonged darkadapted fish, and some evidence for this has been provided. It is important to record from other cells in the white perch retina and explore the vigor of cone-mediated responses in prolonged dark-adapted retinas. It will also be of interest to determine whether cone-mediated responses in other species are depressed in prolonged darkness.

It has long been recognized that in bright light, rod photoreceptors saturate and that rod responses can no longer be elicited in any retinal cell above a certain background illumination. Suppression of cone pathway responsiveness in prolonged darkness has not generally been thought to be the case, although this would appear useful since darkness acts as a stimulus for many retinal cells (Dowling and Ripps, 1973; Dowling, 1987). That is, it has generally been supposed that cones and cone pathways remain active and functional regardless of the adaptive state of the retina. The present experiments suggest that the notion that cone pathways remain fully functional in prolonged darkness may not be correct.

\section{Neuromodulation}

The mechanisms by which the retina modifies cone horizontal cell responsiveness in prolonged darkness in the teleost may serve as a model for neuromodulation in neural tissue. That is, it is generally recognized that two types of neuroactive substances are released from synaptic sites in the brain, neurotransmitters and neuromodulators. Neurotransmitters act directly on the postsynaptic membrane, altering membrane conductance and inducing rapid changes in membrane potential and/or resistance of the cells. Neuromodulators, on the other hand, appear to alter neuronal function in more indirect ways. Often they activate enzyme systems in postsynaptic cells and exert their effects via biochemical mechanisms. These effects have a slow onset, and they can last for minutes to hours or longer. Neuromodulators, as their name indicates, modify neural responsiveness rather than initiate activity.

The neuroactive substance believed to be principally involved in mediating the effects of prolonged darkness in fish, dopamine, interacts with receptors on the horizontal cell membrane that are linked to the enzyme adenylate cyclase (Van Buskirk and Dowling, 1981). Thus, in response to dopamine, cyclic AMP levels increase within the horizontal cells, and it is believed that all of the effects of dopamine are mediated by this second messenger. No direct effects of dopamine on membrane potential or membrane resistance of isolated horizontal cells have been seen (Lasater and Dowling, 1985; Knapp and Dowling, 1987), indicating that the effects of dopamine are likely to be mediated biochemically. Furthermore, the long latency required to observe effects and the long duration of the effects, lasting tens of minutes, argue for biochemical mechanisms. Although the evidence is as yet fragmentary, it seems likely that in horizontal cells, as in other systems, the cyclic AMP exerts its effects by activating kinases that phosphorylate specific proteins (Greengard, 1978; McMahon and Dowling, 1987). Phosphorylation is known to alter the properties of proteins, and it is likely that the effects of dopamine are exerted ultimately by the phosphorylation of proteins within the horizontal cells.

Another noteworthy feature of the action of dopamine in this system is that it causes multiple effects on the horizontal cells. In these papers we have shown clearly that dopamine decreases the light responsiveness of the cell and diminishes the electrical coupling between the cells. In addition, it has been reported that dopamine and cyclic AMP analogs substantially decreasc both dark-release and glutamate-induced release of GABA from goldfish horizontal cells (Yazulla and Kleinschmidt, 1982; Yazulla, 1985). GABA is believed to be the transmitter released by many horizontal cells in the retina, and this action of dopamine, like that of diminishing light responsiveness and electrical coupling between cells, can contribute to a decrease in the influence of the horizontal cells in mediating lateral inhibition in the retina. It may be that other effects are also mediated by dopamine and cyclic AMP on horizontal cells.

The cell that contains and presumably releases dopamine in the teleost retina, the interplexiform cell, has features appropriate for a cell involved in neuromodulation. That is, although there are relatively few dopaminergic interplexiform cell perikarya in the inner nuclear layer, these cells have extensive processes that extend widely across the retina. In the region of the horizontal cells, the plexus formcd by the processes of these cells is particularly dense to that it is likely that each cone horizontal cell receives input from several dopaminergic synapses.

Although dopamine and cyclic AMP do not themselves appear to alter membrane conductance directly, evidence is accumulating that they modify the light responsiveness of, and electrical coupling between, horizontal cells by modulating the conductances of various channels in the horizontal membrane. The application of dopamine or cyclic AMP to isolated horizontal cells in white perch decreases the conductance of the gap junctions between adjacent cells (Lasater and Dowling, 1985), and at the same time they increase the excitatory amino acidgated conductance in the cell membrane (Knapp and Dowling, 1987). Other neuromodulators have been shown to alter voltage-gated conductances in neuronal membranes, suggesting that modification of channels may be a common mechanism utilized by neuromodulatory substances.

\section{References}

Dowling, J. E. (1987) The Retina: An Approachable Part of the Brain, Harvard University Press, Cambridge, MA.

Dowling, J. E., and H. Kipps (1971) S-potentials in the skate retina: Intracellular recordings during light and dark adaptation. J. Gen. Physiol. 58: 163-189.

Dowling, J. E., and H. Ripps (1973) Neurotransmission in the distal retina: The effect of magnesium on horizontal cell activity. Nature 242: 101-103.

Dowling, J. E., M. W. Pak, and E. M. Lasater (1985) White perch horizontal cells in culture: Methods, morphology and process growth. Brain Res. 360: 331-338.

Greengard, P. (1978) Nucleotides, Phosphorylated Proteins, and Neuronal Function, Raven, New York. 
Hashimoto, Y., A. Kato, M. Inokuchi, and K. Watanabe (1976) Reexamination of horizontal cells in the carp retina with Procion yellow electrode. Vision Res. 16: 25-29.

Hassin, G. (1979) Pikeperch horizontal cells identified by intracellular staining. J. Comp. Neurol. 186: 529-540.

Kaneko, A. (1971) Electrical connexions between horizontal cells in the dogfish retina. J. Physiol. (Lond.) 213: 95-105.

Kaneko, A., and A. E. Stuart (1984) Coupling between horizontal cells in the carp retina recorded by diffusion of Lucifer yellow. Neurosci. Lett. 47: 1-7.

Knapp, A. G., and J. E. Dowling (1987) Dopamine enhances excitatory amino acid-gated conductances in retinal horizontal cells. Nature 325 : 437-439.

Lasater, E. M., and J. E. Dowling (1985) Dopamine decreases conductance of the electrical junctions between cultured retinal horizontal cells. Proc. Natl. Acad. Sci. USA 82: 3025-3029.

Mangel, S. C., and J. E. Dowling (1985) Responsiveness and receptive field size of carp horizontal cells are reduced by prolonged darkness and dopamine. Science 229: 1107-1109.

Mangel, S. C., and J. E. Dowling (1987) The interplexiform-horizontal cell system of the fish retina: Eflects of dopamine, light stimulation and time in the dark. Proc. R. Soc. London [Biol.] 231: 91-121.

McMahon, D. G., and J. E. Dowling (1987) Cyclic AMP-dependent protein phosphorylation in the teleost retina. Invest. Ophthalmol. Vis. Sci. Suppl. 28: 277.

Mitarai, G., T. Asano, and Y. Miyake (1974) Identification of five types of S-potentials and their corresponding generating sites in the horizontal cells of the carp retina. Jpn. J. Ophthalmol. 18: 161-176.

Naka, K. I., and W. A. H. Rushton (1967) The generation and spread of S-potentials in fish (Cyprinidae). J. Physiol. (Lond.) 192: 437-461.

Negishi, K., and B. Drujan (1978) Effects of catecholamines on the horizontal cell membrane potential in the fish retina. Sens. Proc. 2: 388-395.

Norton, A. C., H. Spekreijse, M. L. Wolbarsht, and H. G. Wagner (1968) Receptive field organization of the S-potential. Science 160: $1021-1022$.

Parthe, V. (1972) Horizontal, bipolar and oligopolar cells in the teleost retina. Vision Res. 12: 395-406.

Piccolino, M., J. Neyton, and H. M. Gerschenfeld (1984) Decrease of gap junction permeability induced by dopamine and cyclic adenosine $3^{\prime}: 5^{\prime}$-monophosphate in horizontal cells of turtle retina. J. Neurosci. 4: $2477-2488$

Stell, W. K., and D. O. Lightfoot (1975) Color-specific interconnections of cones and horizontal cells in the retina of the goldfish. J. Comp. Neurol. 159: 473-502.
Stell, W. K., S. E. Walker, K. S. Chohan, and A. K. Ball (1984) The goldfish nervus terminalis: A luteinizing hormone-releasing hormone and molluscan cardioexcitatory peptide immunoreactive olfactoretinal pathway. Proc. Natl. Acad. Sci. USA 81: 940-944.

Stewart, W. W. (1978) Functional connections between cells as revealed by dye-coupling with a highly fluorescent naphthalimide tracer. Cell 14: 741-759.

Teranishi, T. (1983) Lateral spread of light-induced response at the cell body and axon terminal levels of external horizontal cells in the carp retina. Jpn. J. Physiol. 33: 417-428.

Teranishi, T., K. Negishi, and S. Kato (1983) Dopamine modulates S-potential amplitude and dye-coupling between external horizontal cells in the carp retina. Nature 301: 243-246.

Teranishi, T., K. Negishi, and S. Kato (1984) Regulatory effect of dopamine on spatial properties of horizontal cells in carp retina. $\mathrm{J}$. Neurosci. 4: 1271-1280.

Van Buskirk, R., and J. E. Dowling (1981) Isolated horizontal cells from carp retina demonstrate dopamine-dependent accumulation of cyclic AMP. Proc. Natl. Acad. Sci. USA 78: 7825-7829.

Witkovsky, P., and J. E. Dowling (1969) Synaptic relationshps in the plexiform layers of carp retina. Z. Zellforsch. 100:60-82.

Witkovsky, P., D. A. Burkhardt, and A. R. Nagy (1979) Synaptic connections linking cones and horizontal cells in the retina of the pikeperch (Stizosterdion vitreum). J. Comp. Neurol. 186: 541-560.

Yamada, E., and T. Ishikawa (1965) Some observations on the fine structure of vertebrate retina. Cold Spring Harbor Symp. Quant. Biol. 30: 383-392

Yang, X.-L., K. Tornqvist, and J. E. Dowling (1988a) Modulation of cone horizontal cell activity in the teleost fish retina. I. Effects of prolonged darkness and background illumination on light responsiveness. J. Neurosci. 8: 2259-2268.

Yang, X.-L., K. Tornqvist, and J. E. Dowling (1988b) Modulation of cone horizontal cell activity in the teleost fish retina. II. Role of interplexiform cells and dopamine in regulating light responsiveness. J. Neurosci. 8: 2269-2278.

Yazulla, S. (1985) Evoked efflux of $\left[{ }^{3} \mathrm{H}\right]$ GABA from goldfish retina in the dark. Brain Res. 325: 171-180.

Yazulla, S., and J. Kleinschmidt (1982) Dopamine blocks carriermediated release of GABA from retinal horizontal cells. Brain Res. 233: $211-215$.

Zucker, C. L., and J. E. Dowling (1987) Centrifugal fibers synapse on interplexiform cells in teleost retina. Nature 330:166-168. 